\title{
The Effects of Negative Nominal Rates on the Pricing of American Calls: Some Theoretical and Numerical Insights
}

\author{
Alessia Cafferata ${ }^{1}$, Pier Giuseppe Giribone ${ }^{2}$, Marina Resta ${ }^{1}$ \\ ${ }^{1}$ DIEC, University of Genova, Genova, Italy \\ ${ }^{2}$ Banca Carige, Genova, Italy \\ Email: alessia.cafferata@economia.unige.it, marina.resta@economia.unige.it, piergiribone@dime.unige.it
}

How to cite this paper: Cafferata, A., Giribone, P.G. and Resta, M. (2017) The Effects of Negative Nominal Rates on the Pricing of American Calls: Some Theoretical and Numerical Insights. Modern Economy, 8, 878-887.

https://doi.org/10.4236/me.2017.87061

Received: May 29, 2017

Accepted: July 10, 2017

Published: July 13, 2017

Copyright $\odot 2017$ by authors and Scientific Research Publishing Inc. This work is licensed under the Creative Commons Attribution International License (CC BY 4.0).

http://creativecommons.org/licenses/by/4.0/

\begin{abstract}
The article investigates the effects played on options pricing by negative risk-free rates when the underlying is an equity with null dividends. In such anomalous conditions, in fact, the fair value at early exercise of the American Call would not match the value of the European Call with the same financial features. We originally motivate this assumption with theoretical arguments. We then move to an empirical investigation where we put at work some quasi-closed formulas for pricing an American option and the stochastic trinomial trees algorithm. We then draw the conclusion that from a numerical viewpoint, the bias between the fair value of the American Call and the value of the corresponding. European Call is mainly due to approximation errors, which can be mitigated when Trinomial Stochastic Trees are used.
\end{abstract}

\section{Keywords}

American Options, Quasi-Closed Formulas, Negative Interest Rates, Stochastic Trinomial Trees

\section{Introduction}

As outlined in a recent note from the Actuarial Association of Europe [1], nowadays negative nominal interest rates for long term maturities are observable in both European and American financial markets. In addition to the economic effects, this led to several technical problems, as the existing pricing models do not give proper valuations, so that either the financial position cannot be correctly priced or the results can be questioned [2].

From the financial standpoint, it is therefore necessary to check to what extent the existing pricing models can be adapted to incorporate negative nominal 
rates. This aspect has been already investigated in some research papers: [3] and [4] discuss the issue for options written on interest rates, both from the practical and the theoretical viewpoint; [5], focusing on foreign exchange and index options investigate whether the use of models allowing for negative interest rates can improve option pricing and implied volatility forecasting; [6], discusses a new closed form for option pricing that leads to sensitively lower the error in European options pricing. Besides, [7] adapts the Nelson-Siegel model [8] to include the negative interest. Finally, the Hull and White model [9], has been recently adapted to calibrate in a more proper way when the underlying is a negative interest rate [10]; however, to the best of our knowledge, much less efforts have been devoted to model the effects of negative nominal interest rates in option pricing for other types of underlying.

In particular, some issues might arise in the case of equity that does not pay dividends: finding the fair value at early exercise of an American Call might be tricky, as it could not match the value of a European Call option with the same parameters. The problem is relevant, because of its corporate implications, as the option evaluation could make the difference when valuing a firm.

This paper aims to fill in this gap. Our research question is discussing whether the known approximation formulas can effectively bypass the above highlighted problems. We illustrate an empirical application, where we compare the estimation of a number of quasi-closed formulas, with that provided by the stochastic trinomial trees algorithm, and we highlight how the bias between the fair value of the American Call at early exercise and the value of the corresponding European Call can be strongly mitigated using this latter methodology.

The paper is structured as follows. Section 2 starts by providing a snapshotwise demonstration of why the equivalence between the fair value of the American Call at early exercise and the European Call can be violated, for an underlying with null dividends. The section then contains a brief overview about the approximation schemes employed in the work. Section 3 illustrates the numerical case study with discussion. Section 4 concludes.

\section{Theoretical Issues and Methodology}

\subsection{On the Violation of the Equivalence between American and European Call Value}

Let us denote by $C_{A}=f_{A}(S, K, T, r, q, \sigma)$ the value of an American Call with spot price $S$, strike price $K$, time to expiration $T$, interest rate $r$, dividend yield $q$, and volatility $\sigma$. We also denote by $C_{E}=f_{E}(S, K, T, r, q, \sigma)$ the corresponding value for a European contingent claim. We focus on the wellknown property [11] according to which in case of an underlying with null dividends we have:

$$
f_{A}(S, K, T, r, 0, \sigma)=f_{E}(S, K, T, r, 0, \sigma) .
$$

In the case of negative interest rate, (1) might not be satisfied. The value of a European Call Option, in fact, cannot be lower than the difference between the 
spot price and the actual value of the strike price:

$$
f_{A}(S, T, K, r, 0, \sigma) \geq f_{E}(S, T, K, r, 0, \sigma) \geq S_{t}-K \exp (-r T) .
$$

Besides:

$$
f_{A}(S, T, K, r, 0, \sigma) \geq \max \left[0, S_{t}-K\right],
$$

Joining (2) and (3) we get:

$$
S_{t}-K<S_{t}-K \exp (-r T)
$$

(4) clearly holds if $r>0$. If $r<0$, (4) is no more consistent, because the term in the right-hand side might be either is negative or lower than the value in the left-hand side, as: $\exp (-r T)>1$.

\subsection{Methodology}

Pricing American contingent claims has traditionally represented a stimulating field of analysis as, in contradistinction to European options, they can be exercised at any time before or at maturity. In this case, the Black-Scholes methodology cannot be applied, and it is necessary to use approximations schemes. Reviewing the related literature requires paramount efforts, besides it is out of the scope of this work: the interested reader can refer to [11].

Nevertheless, we are mainly concerned with two sub-groups of the above methods. In the first group, we consider three quasi-closed formulas that conveys in different ways the original idea discussed in [12]. In particular, the Barone-Adesi and Whaley-BAW-model [13] is a quadratic approximation method for pricing exchange-traded American call and put options on commodities and commodity futures. Using the same notational conventions as in Sec.2.1, we consider an American Call option whose underlying has a cost of carry equal to $b=r-q$. When $b \geq r$, ceteris paribus the value of the American Call is equal to that of the European Call so that the Generalized Black-Scholes-GBS-formula for European contingent claims applies:

$$
C_{A}=C_{E}^{(G B S)}+A_{2}\left(S / S^{*}\right)^{y_{2}}, S<S^{*} ; \text { and } C_{A}=S-K, S \geq S^{*},
$$

where $C_{E}^{(G B S)}$ is the value of the European Call according to the GBS formula, and:

$$
A_{2}=S^{*}\left\{1-N\left[d_{1}\left(S^{*}\right)\right] \exp [(b-r) T]\right\} / y_{2} ;
$$

with:

$$
\left.y_{2}=\left\{-\left(2 b / \sigma^{2}-1\right)+\sqrt{\left(2 b / \sigma^{2}-1\right)^{2}+\left(8 r / \sigma^{2}\right) /[1-\exp (r T)}\right]\right\} / 2 .
$$

Finally, $S^{*}$ is the price level such that:

$$
S^{*}-K=C_{E}\left(S^{*}, K, T, r, q, \sigma\right)+S^{*}\left\{1-\exp (-q T) N\left[d_{1}\left(S^{*}\right)\right]\right\} / y_{2} \text {. }
$$

The Newton-Raphson algorithm can be then used to solve (5) with initial value: 


$$
S_{\text {START }}^{*}=K+\left[S_{\infty}^{*}-K\right]\left[1-\exp \left(h_{2}\right)\right]
$$

where:

$$
h_{2}=-K(b T+2 \sigma \sqrt{T}) /\left[S_{\infty}^{*}-K\right] \text {, }
$$

and:

$$
S_{\infty}^{*}=K /\left\{1-2\left[-\left(2 b / \sigma^{2}-1\right)+\sqrt{\left(2 b / \sigma^{2}-1\right)^{2}+8 r / \sigma^{2}}\right]^{-1}\right\},
$$

so that the best $S_{i+1}$ estimator is given by:

$$
S_{i+1}=\left[K+R H S\left(S_{i}\right)-b_{i} S_{i}\right] /\left(1-b_{i}\right),
$$

where $R H S\left(S_{i}\right)$ is the right-hand side of (5) at the $\mathrm{i}$-th step.

The second method is due to Bjerksund and Stensland- $\mathrm{BS}_{1993}$-and it is more general than the BAW, as the underlying can be a stock, a future or an exchange rate, and it is based on a feasible but non-optimal exercise strategy corresponding to a trigger price $I$ [14]. If $S>I$, it is optimal to exercise the option immediately, and the value must be equal to the intrinsic value $S$ - $K$. On the other hand, if $S \leq I$, it will never be optimal to exercise the American call option before expiration, and the value can be found using the Black-Scholes formula. Finally, the third approximation method is due to Bjerksund and Stensland, again [15] BS2002-, and it is based on the extension of the flat boundary concept by dividing the time to maturity into two parts, and allowing two separate flat boundaries in each of them.

An alternative to the above-mentioned approximation methods is represented by stochastic binomial and trinomial trees. Assuming the stock price to follow a discrete time process, in the binomial tree scheme [16] the life of the option until the maturity $T$ is decomposed into $N$ time steps of equal length. At each time step, the underlying will move either up or down by a specific factor $u=\exp (\sigma \sqrt{\Delta t})$ or $d=\exp (-\sigma \sqrt{\Delta t})$, with probability $p$ and $1-p$, respectively. The value of the America Call exercised at expiration is:

$$
C_{E}^{(B I N)}=\exp (-r T) \sum_{i=0}^{N}\{N ! /[i !(N-i) !]\} p_{u}^{i}\left(1-p_{u}\right)^{N-i} \max \left(S u^{i} d^{N-i}-K, 0\right)
$$

where: $p_{u}=\{\exp [(r-q) \Delta t]-d\} /(u-d)$.

To properly assess $C_{E}$ in case of early exercise, at each node of the three the following pay-off must be applied:

$$
\max \left\{S_{i, j}-K, \exp (-r \Delta t)\left[p_{u} f_{i, j+1}+\left(1-p_{u}\right) f_{i, j}\right]\right\},
$$

where $f_{i, j}$ is the value of the Call for the node of position $(i, j)$ in the tree. The initial value of the option can be then derived by way of the standard backward induction technique. A straightforward extension of this procedure is given by the trinomial scheme algorithm [17], with the underlying that can now assume three different states: up, down or unchanged. The increase in the number of possible states allows to lower the number of necessary steps for the convergence of the procedure, without any loss in the estimation accuracy. The size of the 
jumps is usually set to: $u=\exp (\sigma \sqrt{2 \Delta t})$, and $d=\exp (-\sigma \sqrt{2 \Delta t})$, so that the probability of reaching upward/downward branches is given by:

$$
\begin{gathered}
p_{u}=\{[\exp (b \Delta t / 2)-\exp (-\sigma \sqrt{\Delta t / 2})] /[\exp (\sigma \sqrt{\Delta t / 2})-\exp (-\sigma \sqrt{\Delta t / 2})]\}^{2} \\
p_{d}=\{[\exp (\sigma \sqrt{\Delta t / 2})-\exp (b \Delta t / 2)] /[\exp (\sigma \sqrt{\Delta t / 2})-\exp (-\sigma \sqrt{\Delta t / 2})]\}^{2} \text { while }
\end{gathered}
$$
the probability $p_{m}$ of reaching the intermediate node is: $p_{m}=1-p_{u}-p_{d}$.

\section{Examples and Discussion}

We consider three scenarios (A, B, and C), and for each of them we compute the value of the American Call with the approximation schemes illustrated in Sec. 2.2. In detail:

- A represents a typical market situation, with a positive risk-free rate, and with a dividend-paying stock as underlying;

- B simulates a market situation with a positive risk-free rate, and with a null dividend stock as underlying: in this case, as $r>0$, Equation (1) holds;

- $\mathrm{C}$ considers an atypical situation, with a negative risk-free rate. The underlying stock, likewise in the B case, does not pay any dividend.

The parameters employed in the simulation are reported in Table 1: we have used the annualized value of the volatility, while $T$ is expressed as a fraction of the year; finally, the value of $r$ in the third scenario corresponds to the 3-months value of the Euribor at 9 September 2016, as provided by Bloomberg.

The simulation results are shown in Table 2, where we employed the following abbreviations: BAW to indicate the Barone-Adesi and Whaley model, BS1993 and BS2002 referring to 1993 and 2002 Bjerksund and Stensland approximation formulas, respectively, and T-TREE for the trinomial tree. In this latter case, the discretization steps were set to $N=9000$.

Looking at Table 2, several remarks come out. First, in the scenario A, by construction, the early exercise of the American call is sometimes optimal, and this is duly taken into consideration by every approximation scheme. In the scenario $B$, as it replicates a situation where the early exercise is never optimal and (1) holds, all the examined schemes have properly applied the Black-Scholes

Table 1. Parameters employed in the three scenarios simulation.

\begin{tabular}{cccc}
\hline \multirow{2}{*}{ Parameters } & \multicolumn{3}{c}{ Scenarios } \\
\cline { 2 - 4 } & A & B & C \\
\hline$K$ & 100 & 100 & 100 \\
$r$ & 100 & 100 & 100 \\
$q$ & $10 \%$ & $10 \%$ & $-0.301 \%$ \\
$b$ & $10 \%$ & 0 & 0 \\
$T$ & 0 & $10 \%$ & $-0.301 \%$ \\
& $25 \%$ & $25 \%$ & $25 \%$ \\
\hline
\end{tabular}


Table 2. Simulation results for the three scenarios under different estimation models.

\begin{tabular}{cccc}
\hline & \multicolumn{3}{c}{ Scenarios } \\
\cline { 2 - 4 } Scheme & $\mathrm{A}$ & $\mathrm{B}$ & $\mathrm{C}$ \\
\hline BAW & 4.8908 & 6.2545 & 4.9479 \\
BS1993 & 4.8765 & 6.2545 & 4.9479 \\
BS2002 & 4.8802 & 6.2545 & 4.9479 \\
T-TREE & 4.8801 & 6.2544 & 5.0461 \\
\hline
\end{tabular}

formula for the European Call. In the third case, the methods relying on quasi-closed approximation formulas (BAW, BS1993 and BS2002) have still exploited (1) which is no more verified, so that they all incorrectly estimated the American Call value. On the other hand, the T-TREE scheme generated a more robust estimation, because the convenience for the early exercise was checked on each node of the tree. As preliminary conclusion, we can therefore state that using the trinomial trees rather than other approximation schemes might be preferable, as this methodology seems being more robust to anomalous parameters values.

We then moved one step further, giving additional instruments to evaluate such robustness. To such aim, we focused on the scenario C (i.e. the one where critical issues arose) and we studied the behaviour of the estimation errors using the T-TREE (Error ${ }_{\text {T-TREE }}$ ) and the BS2002 (Error ${ }_{\text {BS2002 }}$ ) schemes, varying once per time S, K, T, $\sigma$ and $\mathrm{r}$. The choice of BS2002 is motivated as it is generally acknowledged to be the more accurate among the examined quasi-closed formulas. Figure 1 shows the behaviour of the variable Error $=$ Error $_{\text {T-TREE }}-$ Error $_{\text {Bs2002 }}$.

Looking at the results, from Figure 1(a) we observe that, varying the spot value $S$, Error lies within the interval [0.02,0.35], and tends to increase, originally in a more than proportional fashion. This suggests the existence of model risk, raising as the option's moneyness increases. Similar considerations apply also to the behaviour of Error with respect to the strike price K, shown in Figure 1(b). In this second case, in fact, the lower $\mathrm{K}$ (high moneyness) the higher Error is, i.e. the higher the gap between the T-TREE and the best quasi-closed approximation method. In the case of the time to maturity $\mathrm{T}$, observable in Figure 1(c), the divergence between T-TREE and BS2002 is very evident, with Error varying in the range $[0.05,0.5]$ : the longer the hedging period, the worst the performance of conventional methods is. For what is concerning the behaviour of Error varying r, Figure 1(d) examines only the case of negative risk-free rates. In this case, we can observe an elbow-like curve, with higher Error values (more than 0.1) concentrated around lowest (and quite unrealistic) negative nominal rates. In every case, as $r<0$, Error never falls under the 0.09 threshold. Finally, from Figure 1 (e) we can state that there is a positive correlation between the behaviour of Error and $\sigma$, with the former monotonically growing as the annualized volatility increases.

We then examined the impact of different approximation schemes on the 


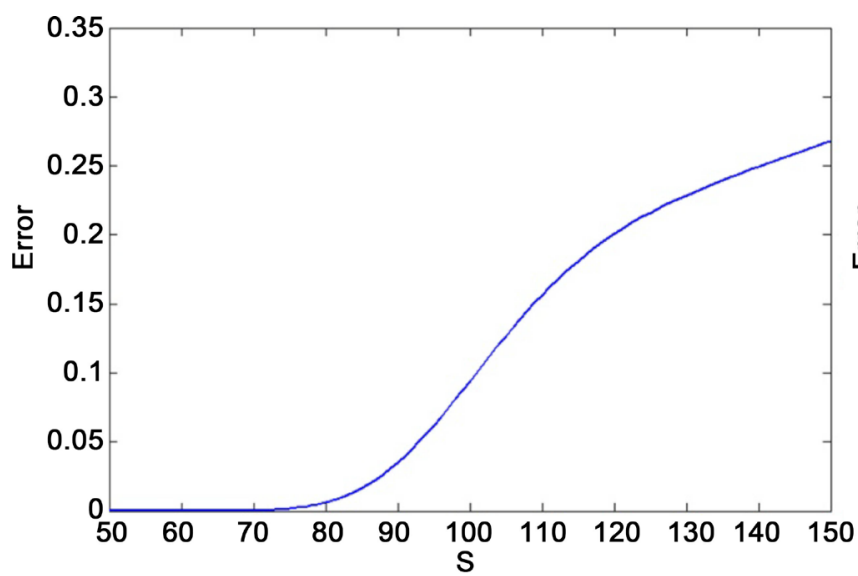

(a)

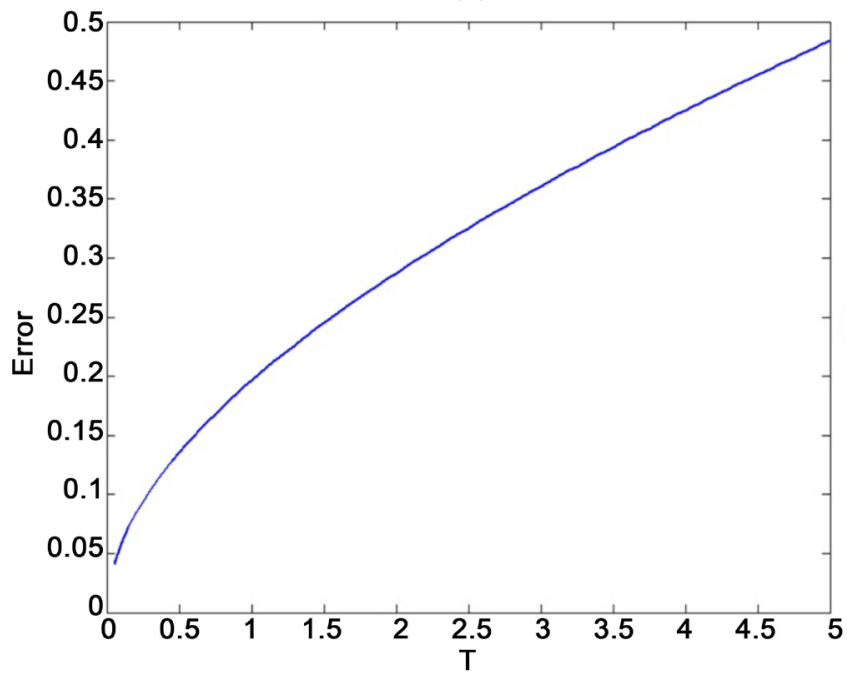

(c)

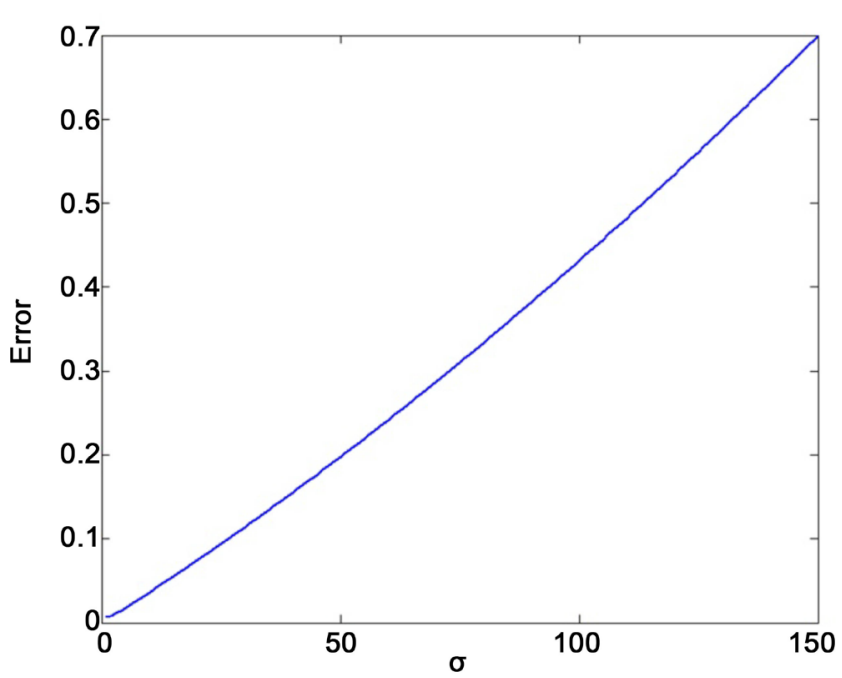

(e)

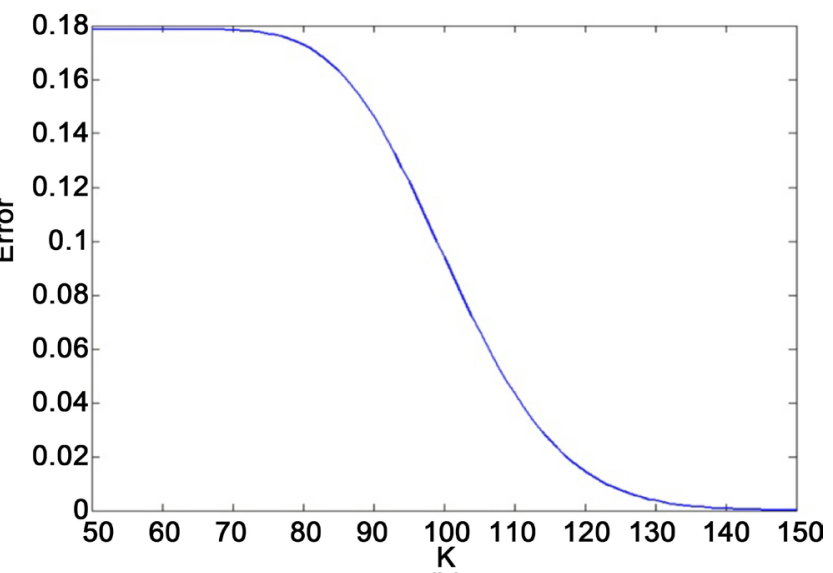

(b)

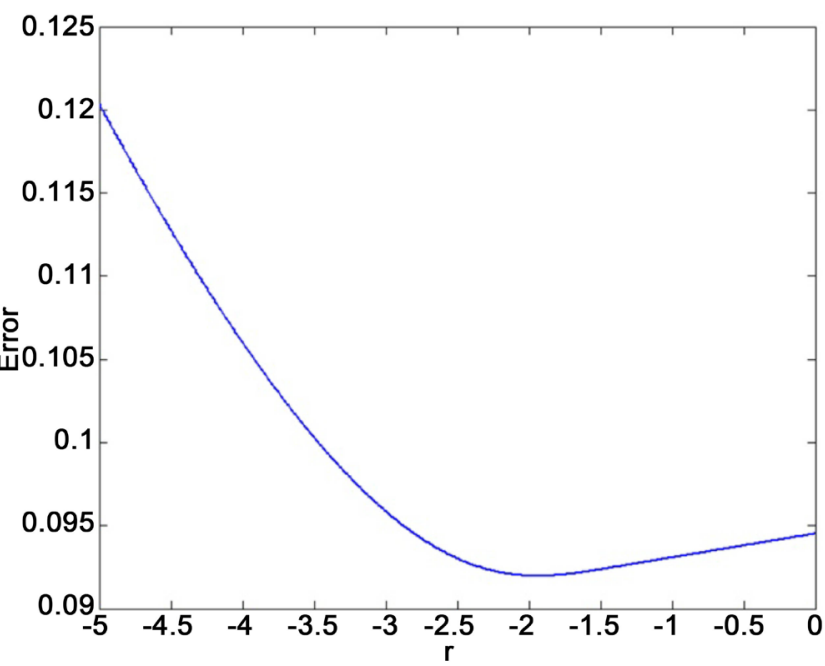

(d)

Figure 1. From top to bottom and from left to right: behaviour of error varying $\mathrm{S}(a), \mathrm{K}(b), \mathrm{T}(c), \mathrm{r}(d)$, and $\sigma(e)$.

value of the most used Greeks [11], because of the paramount role that they play in the hedging activity. We therefore evaluated Delta $(\Delta)$, Vega $(v)$, and Theta $(\Theta)$, being: 


$$
\Delta=\partial C_{A} / \partial S ; \quad v=\partial C_{A} / \partial \sigma ; \quad \Theta=\partial C_{A} / \partial T,
$$

where $C_{A}$ is the option value, and $S, \sigma$ and $T$ are as usual. Table 3 contains the estimated values.

From the results in Table 3, we look at replicating the situations already discussed in the first sensitivity analysis, with all the methods generating the same values for each Greek in the Scenarios A and B, and with the T-TREE scheme providing different results in the case $\mathrm{C}$.

\section{Conclusion}

In this paper, we examined how the existing numerical schemes react in the pricing of an American Call option, in presence of anomalous conditions. We focused on the case of negative risk-free rate and zero dividends stock as underlying and we put at work three quasi-closed approximation formulas and the Trinomial Trees technique. We then analysed three toy scenarios, replicating different market conditions, to conclude that in the case of negative risk-free rate it should be preferable pricing the American Calls by way of the Trinomial tree (T-TREE) scheme. This is because unlike the other techniques, T-TREE does not price the American Call using the equivalence between its fair value at early exercise and the corresponding value of the European Call with the same financial features, but rather the convenience for the early exercise is checked on each node of the tree. In this way, the T-TREE is protected from the risk that this property is no longer valid, as it happens in case of negative nominal rates. Moreover, in such anomalous conditions, the accuracy of the T-TREE with respect to the other methods is very robust to both hard negative values of the risk-free rate, and to increases with respect to the moneyness of the underlying,

Table 3. The impact of different approximation schemes on the value of Delta, Vega and Theta Greeks.

\begin{tabular}{|c|c|c|c|}
\hline \multirow{2}{*}{ Greeks } & \multicolumn{3}{|c|}{ Scenarios } \\
\hline & A & B & $\mathrm{C}$ \\
\hline$\Delta_{\mathrm{BAW}}$ & 0.5156 & 0.6035 & 0.5225 \\
\hline$\Delta_{\mathrm{BS} 1993}$ & 0.5151 & 0.6035 & 0.5225 \\
\hline$\Delta_{\mathrm{BS} 2002}$ & 0.5154 & 0.6035 & 0.5225 \\
\hline$\Delta_{\text {T-TREE }}$ & 0.5152 & 0.6033 & 0.5294 \\
\hline$v_{\text {BAW }}$ & 19.5379 & 19.2716 & 19.9153 \\
\hline$v_{\mathrm{BS} 1993}$ & 19.4847 & 19.2716 & 19.9153 \\
\hline$v_{\mathrm{BS} 2002}$ & 19.4951 & 19.2716 & 19.9153 \\
\hline$v_{\text {T-TREE }}$ & 19.5035 & 19.2714 & 20.3289 \\
\hline$\Theta_{\text {BAW }}$ & -9.4356 & -15.0457 & -9.8153 \\
\hline$\Theta_{\text {BS1993 }}$ & -9.3404 & -15.0457 & -9.8153 \\
\hline$\Theta_{\text {BS2002 }}$ & -9.3612 & -15.0457 & -9.8153 \\
\hline$\Theta_{\text {T-TREE }}$ & -9.3662 & -15.0424 & -10.0203 \\
\hline
\end{tabular}


as well as of the volatility and the maturity of the option.

Future research plans include increasing the robustness of our survey at least towards two directions: i) by extending the number of approximation methods under comparison, and ii) by considering additional tests to address the error significance.

\section{Acknowledgements}

The authors would like to thank the anonymous reviewers for their valuable comments and suggestions to improve the quality of the paper.

\section{References}

[1] European Actuarial Association (2016) Negative Interest Rates and Their Technical Consequences, 16 December 2016.

http://actuary.eu/documents/AAE-negative-interest-rates_FINAL-161216.pdf

[2] Kooiman, T. (2015) Negative Rates in Financial Derivatives. Master thesis, Amsterdam University, Amsterdam.

[3] Giribone, P.G., Ligato, S. and Mulas, M. (2017) The Effects of Negative Interest Rates on the Estimation of Option Sensitivities: The Impact of Switching from a Log-Normal to a Normal Model. International Journal of Financial Engineering, 4, 1750015. https://doi.org/10.1142/S2424786317500153

[4] Giribone, P.G. and Ligato, S. (2016) Considerazioni sullo stato attuale della valorizzazione delle opzioni cap e floor aventi come parametro di riferimento il tasso EURIBOR. AIAF Newsletter, 99, 45-53.

[5] Recchioni, M.C., Sun, Y. and Tedeschi, G. (2017) Can Negative Interest Rates Really Affect Option Pricing? Empirical Evidence from an Explicitly Solvable Stochastic Volatility Model. Quantitative Finance, 1-19. https://doi.org/10.1080/14697688.2016.1272763

[6] Abudy, M. and Izhakian, Y. (2013) Pricing Stock Options with Stochastic Interest Rate. International Journal of portfolio Analysis and Management, 1, 250-277.

[7] Inui, K. (2015) Improving Nelson-Siegel Term Structure Model under Zero/SuperLow Interest Rate Policy. World Risk and Insurance Economics Congress. http://www.wriec.net/wp-content/uploads/2015/07/3B1_Koji.pdf

[8] Nelson, C. and Siegel, A.F. (1987) Parsimonious Modeling of Yield Curves. Journal of Business. 60, 473-489. https://doi.org/10.1086/296409

[9] Hull, J. and White, A. (1994) Numerical Procedures for Implementing Term Structure Models I. Journal of Derivatives, 2, 7-16. https://doi.org/10.3905/jod.1994.407902

[10] Hull, J. and White, A. (2015) A Generalized Procedure for Building Trees for the Short Rate and its Application to Determining Market Implied Volatility Functions. Quantitative Finance, 15, 443-454. https://doi.org/10.1080/14697688.2014.961530

[11] Hull, J. (2014) Options, Futures and Other Derivatives. 9th Edition, Prentice Hall, Upper Saddle River.

[12] Roll, R. (1977) An Analytic Valuation Formula for Unprotected American Call Options on Stocks with Known Dividends. Journal of Financial Economics, 5, 251-258.

[13] Barone-Adesi, G. and Whaley, R.E. (1987) Efficient Analytic Approximation of American Option Values. Journal of Finance, 42, 301-320.

https://doi.org/10.1111/j.1540-6261.1987.tb02569.x 
[14] Bjerksund, P. and Stensland, G. (1993) Closed-Form Approximation of American Options. Scandinavian Journal of Management, 9, 87-99.

[15] Bjerksund, P. and Stensland, G. (2002) Closed-Form Valuation of American Options, Norwegian School of Economics and Business Administration. Department of Finance and Management Science, Discussion Paper, 9. https://brage.bibsys.no/xmlui/handle/11250/163705

[16] Cox, J., Ross, S. and Rubinstein, M. (1979) Option Pricing-A Simplified Approach. Journal of Financial Economics, 7, 229-263.

[17] Boyle, P.P. (1986) Option Valuation Using a Three-Jump Process. International Options Journal, 3, 5-12.

Submit or recommend next manuscript to SCIRP and we will provide best service for you:

Accepting pre-submission inquiries through Email, Facebook, LinkedIn, Twitter, etc. A wide selection of journals (inclusive of 9 subjects, more than 200 journals)

Providing 24-hour high-quality service

User-friendly online submission system

Fair and swift peer-review system

Efficient typesetting and proofreading procedure

Display of the result of downloads and visits, as well as the number of cited articles Maximum dissemination of your research work

Submit your manuscript at: http://papersubmission.scirp.org/

Or contact me@scirp.org 